\title{
Atypical Presentation of Congenital Triangular Alopecia: A Case Series in Italy
}

\author{
Michela Starace ${ }^{1}$, Miriam Anna Carpanese ${ }^{1}$, Diego Abbenante ${ }^{1}$, Francesca Bruni ${ }^{1}$, \\ Bianca Maria Piraccini ${ }^{1}$, Aurora Alessandrini ${ }^{1}$
}

1 Department of Experimental, Diagnostic and Specialty Medicine, Division of Dermatology, University of Bologna, Italy

Key words: congenital triangular alopecia, scalp, trichoscopy, atypical

Citation: Starace M, Carpanese MA, Abbenante D, Bruni F, Piraccini BM, Alessandrini A. Atypical presentation of congenital triangular alopecia: a case series in Italy. Dermatol Pract Concept. 2020;10(4):e2020122. DOI: https://doi.org/10.5826/dpc.1004a122

Accepted: July 3, 2020; Published: October 26, 2020

Copyright: (02020 Starace et al. This is an open-access article distributed under the terms of the Creative Commons Attribution License (CC-BY-NC-4.0), which permits unrestricted noncommercial use, distribution, and reproduction in any medium, provided the original author and source are credited.

Funding: None.

Competing interests: The authors have no conflicts of interest to disclose.

Authorship: All authors have contributed significantly to this publication.

Corresponding author: Miriam Anna Carpanese, MD, Department of Experimental, Diagnostic and Specialty Medicine-Division of Dermatology, University of Bologna, Via Massarenti, 1, 40138 Bologna, Italy. Email: miriam.carpanese@gmail.com

\footnotetext{
ABSTRACT Background: Congenital triangular alopecia (CTA) is a benign, asymptomatic, nonprogressive, localized and noncicatricial type of alopecia that is usually first noted during infancy or childhood. The pattern of hair loss is traditionally described as triangular, oval or lancet shaped with apex toward the vertex.

Objective: We present a case series of CTA located in unusual sites.

Patients and Methods: We performed trichoscopy in 78 patients with CTA. From this group, we selected 10 individuals (4 males and 6 females) whose disease was not localized on the typical scalp area.

Results: The alopecic area was located on the occipital region in 5 patients, the parietal region in 4 patients, at the vertex in 1 . With trichoscopy, vellus hairs were detected in all patients, and evidence of empty follicles was noticed only in 3 patients.

Conclusions: In contrast with the preconceived notion that all CTAs are frontotemporal, our case series points out that this disease could be localized in other scalp sites
}

\section{Introduction}

Congenital triangular alopecia (CTA) is a benign, asymptomatic, nonprogressive, localized and noncicatricial type of alopecia that is usually first noted during infancy or childhood. Previously other names have been used to describe this condition, such as Brauer nevus or temporal triangular alopecia. CTA most commonly affects the frontotemporal region of the scalp in a unilateral pattern, more frequently involving the left side. In a minority of cases a bilateral involvement has been reported [1]. The pattern of hair loss is traditionally described as triangular, oval, or lancet-shaped with the apex toward the vertex [2]. The diagnosis is mainly based on its clinical appearance, and usually pathology is not 
needed to confirm the diagnosis. Trichoscopy can be useful in excluding other diseases characterized by localized alopecia [3], such as alopecia areata. Herein, we present a case series of CTA located in unusual sites.

\section{Methods}

During the period from 2012 to 2020, at outpatient hair consultation of the Department of Experimental, Diagnostic and Specialty Medicine at the University of Bologna, we diagnosed 78 patients with CTA. In all patients we performed trichoscopy using a FotoFinder dermatoscope. From this group, we selected 10 individuals $(12.8 \%)$ whose disease was not localized in the typical scalp area. All the patient's data are summarized in Table 1.

\section{Results}

In this group there were 6 males and 4 females with a mean age of 3.5 years. Regarding the location on the site, the alopecic area was located on the occipital region in 5 patients, the parietal region in 4 patients, and at the vertex in 1 patient (Figure 1, A and B). With trichoscopy, vellus hairs were detected in all patients, and evidence of empty follicles was noticed only in 3 patients (Figure 1, C and D).

\section{Discussion}

CTA is a non-scarring type of alopecia. Its exact incidence is not known, but some studies reported an estimated rate of $0.11 \%$ [4]. Most CTAs present in children between 3 and 6 years old, but it can also occur in adult patients. According to Kumar Dey et al [5], as of 2016, only 127 cases had been reported worldwide. It usually appears in a sporadic form, but familial cases have been described [6,7]. In a smaller percentage of cases, about $15 \%$, CTA can be associated with other disorders or syndromes, such as phacomatosis pigmentovascularis $[8,9]$. To date, the etiology is unknown, and no specific treatments are available for this benign condition. Despite the typical presentation of CTA as a triangular or oval patch of circumscribed alopecia localized in the frontotemporal area, some authors reported atypical locations of CTA in the mid-frontal region of the scalp [10], the occipital area [11], the left temporo-parietal-vertex region of the scalp [12], and the eyebrows [13]. The diagnosis of CTA is mainly based on its clinical appearance and location. Pathology shows miniaturized follicles that replace terminal hairs, with an increased proportion of vellus or indeterminate hairs. The total number of follicle units is in the normal range [1], but it is not usually performed. The differential diagnoses of the disease include alopecia areata, trichotillomania, traction alopecia, and congenital aplasia cutis.

Several cases reported in literature show that CTA could be misdiagnosed and incorrectly treated as other forms of focal alopecia, principally alopecia areata $[11,14]$. For this reason, trichoscopy can be useful, avoiding scalp biopsy or useless treatments. Typical trichoscopic findings include normal follicular openings with vellus hairs covering the alopecic area and terminal hairs on the outskirt of the lesion [15]. Classic signs of alopecia areata, black or yellow dots or exclamation marks, are absent in CTA. Inui et al [16] proposed 4 diagnostic criteria for CTA: triangular or spearshaped area of alopecia involving the frontotemporal region of the scalp; trichoscopic features of normal follicular openings with vellus hair surrounded by normal terminal hair and absence of yellow and black spots, dystrophic hairs and

Table 1. Clinical Data from Patients With CTA Localized on Atypical Scalp Area

\begin{tabular}{|c|c|c|c|c|}
\hline Case Number & Age & Sex & Site & VDS \\
\hline 1 & 3 & $\mathrm{M}$ & Occipital & Vellus hair \\
\hline 2 & 5 & $\mathrm{M}$ & Parietal & Vellus hair \\
\hline 3 & 1 & $\mathrm{~F}$ & Occipital & Vellus hair and empty follicles \\
\hline 4 & 4 & $\mathrm{~F}$ & Parietal & Vellus hair \\
\hline 5 & 5 & $\mathrm{~F}$ & Occipital & Vellus hair \\
\hline 6 & 4 & M & Occipital & Vellus hair and empty follicles \\
\hline 7 & 2 & $\mathrm{~F}$ & Parietal & Vellus hair and empty follicles \\
\hline 8 & 3 & M & Parietal & Vellus hair \\
\hline 9 & 4 & M & Occipital & Vellus hair \\
\hline 10 & 3 & $\mathrm{~F}$ & Vertex & Vellus hair \\
\hline
\end{tabular}

$\mathrm{CTA}=$ congenital triangular alopecia VDS = videodermoscopy 


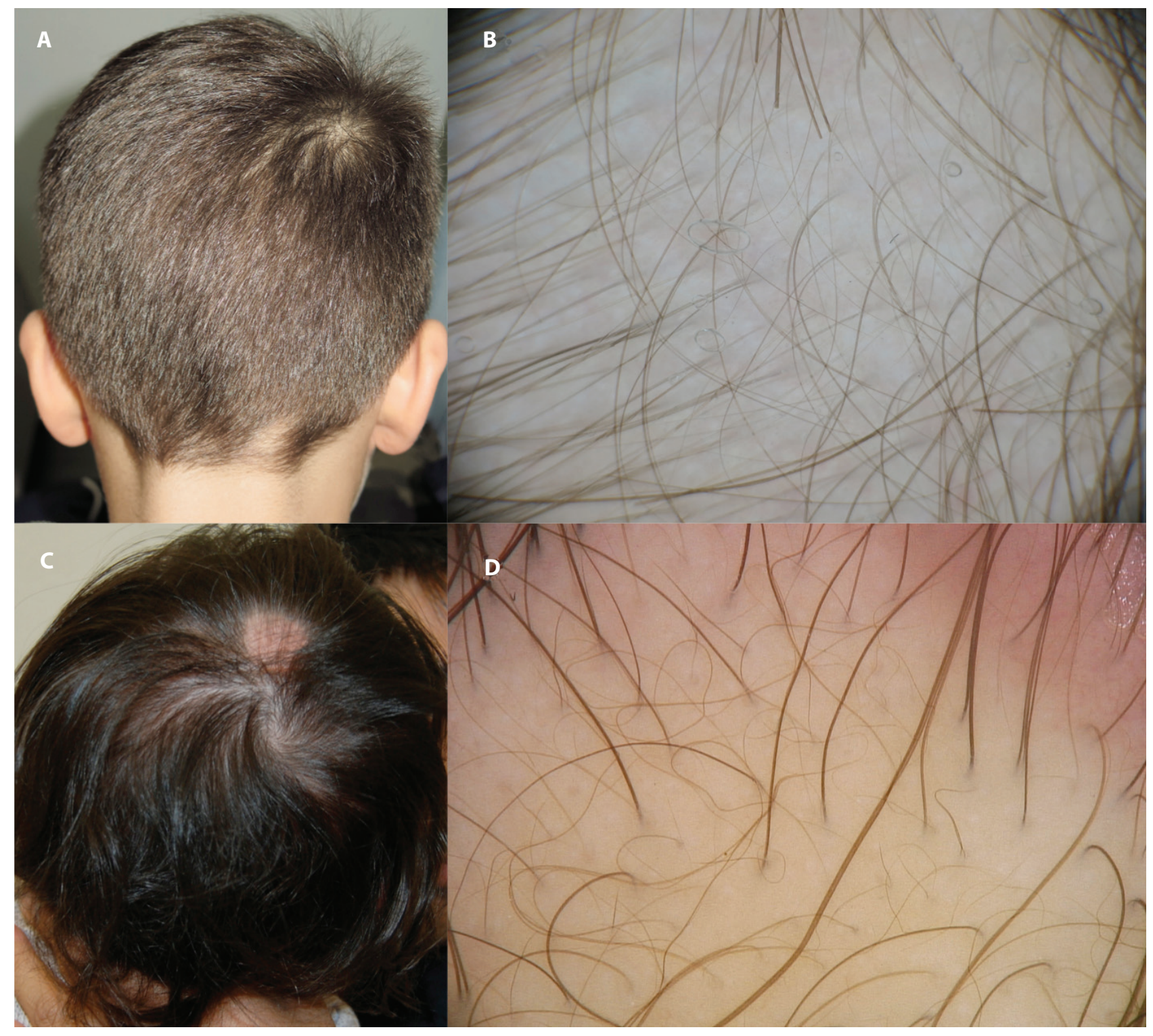

Figure 1. Two cases of our series: (A) occipital CTA; (B) vertex CTA. With trichoscopy, vellus hairs are evident (C, D), but also empty follicles (D). CTA = congenital triangular alopecia.

decreased follicular openings; and persistence of no significant hair growth after dermoscopic and clinical confirmation of the existence of vellus hairs. Our cases fulfill all the criteria for CTA except the site of involvement.

\section{Conclusions}

In contrast with the preconceived notion that all CTAs are frontotemporal, our case series points out that this disease could be localized in other scalp sites. This focus is important because CTA is an underdiagnosed condition, and in order to avoid redundant therapies, it should be included in differential diagnosis when evaluating a circumscribed hairless patch on the scalp.

\section{References}

1. Trakimas C, Sperling LC, Skelton HG 3rd, Smith KJ, Buker JL. Clinical and histologic findings in temporal triangular alopecia. J Am Acad Dermatol.1994;31(2 Pt 1):205-209. DOI: 10.1016/ S0190-9622(94)70147-4.

2. Trakimas CA, Sperling LC. Temporal triangular alopecia acquired in adulthood. J Am Acad Dermatol. 1999;40(5 Pt 2):842844. DOI: 10.1053/jd.1999.v40.a97651. PMID: 10321631.

3. Yin Li VC, Yesudian PD. Congenital triangular alopecia. Int J Trichology. 2015;7(2):48-53. DOI: 10.4103/09747753.160089. PMID: 26180448.

4. García-Hernández MJ, Rodríguez-Pichardo A, Camacho F. Congenital triangular alopecia (Brauer nevus). Pediatr Dermatol. 1995;12(4):301-303. DOI: 10.1111/j.1525-1470.1995. tb00187.x. PMID: 8747572. 
5. Dey VK, Bhadoria TS, Saxena A, Jaisinghani AK, Patil AY, Dubey N. Congenital triangular alopecia: the 127 (th) case. Int J Trichology. 2016;8(1):50-51. DOI: 10.4103/09747753.179399. PMID: 27127384

6. Patrizi A, Morrone P, Fiorentini C, Bianchi T. An additional familial case of temporal triangular alopecia. Pediatr Dermatol. 2001;18(3):263-264. DOI: 10.1111/j.1525-1470.2001.19144.x.

7. Ruggieri M, Rizzo R, Pavone P, Baieli S, Sorge G, Happle R. Temporal triangular alopecia in association with mental retardation and epilepsy in a mother and daughter. Arch Dermatol. 2000;136(3):426-427. DOI: 10.1001/archderm.136.3.426. PMID: 10724218.

8. Oliveira LC, Miranda AR, Pinto SA, Ianhez M. Case for diagnosis. Alopecia areata and congenital triangular alopecia. An Bras Dermatol. 2014;89(2):353-355. DOI: 10.1590/abd18064841.20142740. PMID: 24770522.

9. León-Muiños E, Monteagudo B, Labandeira J, Cabanillas M. [Bilateral congenital triangular alopecia associated with congenital heart disease and renal and genital abnormalities]. Actas Dermosifiliogr. 2008;99(7):578-579. DOI: 10.1016/S15782190(08)70322-6.

10. Goldust M, Rahmatpour Rokni G, Sadr S, Mirabi A, Rezaee E, Goren A, Lotti T. Anterior, frontal congenital triangular alope- cia, redundancy in therapy without improvement. Dermatol Ther. 2018;31(6):e12698. DOI: 10.1111/dth.12698. PMID: 30284356.

11. Jamwal A, Sharma SD. Congenital triangular alopecia. Indian Pediatr. 2014;51(6):511.

12. Singh N, Goyal A, Thappa DM, Rajesh NG. Congenital triangular alopecia: is it always confined to fronto-temporal region? Indian J Dermatol Venereol Leprol. 2016;82(1):112. DOI: 10.4103/0378-6323.157456. PMID: 26728834.

13. Yadav D, Khandpur S, Subhadarshani S, Sahni K. Congenital symmetrical circumscribed patterned non-scarring alopecia of eyebrows: a variant of congenital triangular alopecia or an anatomical variation? BMJ Case Rep. 2019 ;12(5): e227472. DOI: 10.1136/bcr-2018-227472. PMID: 31129634.

14. Yamazaki M, Irisawa R, Tsuboi R. Temporal triangular alopecia and a review of 52 past cases. J Dermatol. 2010;37(4):360-362. DOI: 10.1111/j.1346-8138.2010.00817.x. PMID: 20507407.

15. Iorizzo M, Pazzaglia M, Starace M, Militello G, Tosti A. Videodermoscopy: a useful tool for diagnosing congenital triangular alopecia. Pediatr Dermatol. 2008;25(6):652-654. DOI: 10.1111/j.1525-1470.2008.00811.x. PMID: 19067883.

16. Inui $S$, Nakajima $T$, Itami $S$. Temporal triangular alopecia: trichoscopic diagnosis. J Dermatol. 2012;39(6):572-574. DOI: 10.1111/j.1346-8138.2011.01348.x. PMID: 21906133. 